\title{
Epidemic Response Archetypes: Negotiating Unknowns in Pandemic Planning
}

\section{By Tess Laidlaw}

From beyond Canada's borders, the disease made a slow but ominous entrance into the country. Early cases progressed quickly and treatments seemed ineffectual. Uncertainty regarding the presence of the disease fueled alarm and rampant speculation, while its unusual epidemiology caused confusion as cases appeared among those normally considered least susceptible to infection. Amid the upheaval, the press reported that "a panic of an almost indescribable nature seems to have taken hold."

The disease described above is not influenza A H1N1 but cholera, and the year is not 2009 but 1832. Yet, the sense of what made one vulnerable or safe and the fear of a rampaging, mysterious infection seems oddly familiar. Societies have responded to epidemic diseases in similar ways through history, yet the manner in which people interpret the risks posed by new diseases remains relatively unexplored by the medical community. ${ }^{2}$ Such knowledge would be invaluable in pandemic planning.

Ideas about how diseases are caused or prevented have both intellectual and social counterparts. ${ }^{3}$ Medical historian Charles Rosenberg describes epidemics as accompanied by "archetypical" responses: As societies strive to make sense of outbreaks, patterned methods of interpretation recur. ${ }^{3}$ To illustrate, many methods of protection from diseases have existed through history and were generally based on medical knowledge of the time. However, some were purely symbolic, such as scapegoating, which emphasizes the perceived high-risk status of an "Other," ${ }^{4}$ a person or group that symbolically ensures one's own safety. Scapegoating could, in pandemic situations, lead to victimization of targeted groups. ${ }^{2}$ While cholera infection in the 1830 s was related to perceived moral failings of immigrants, ${ }^{1}$ early media coverage of H1N1 in Canada highlighted the threat posed by Mexico as the source of risk. ${ }^{5,6}$

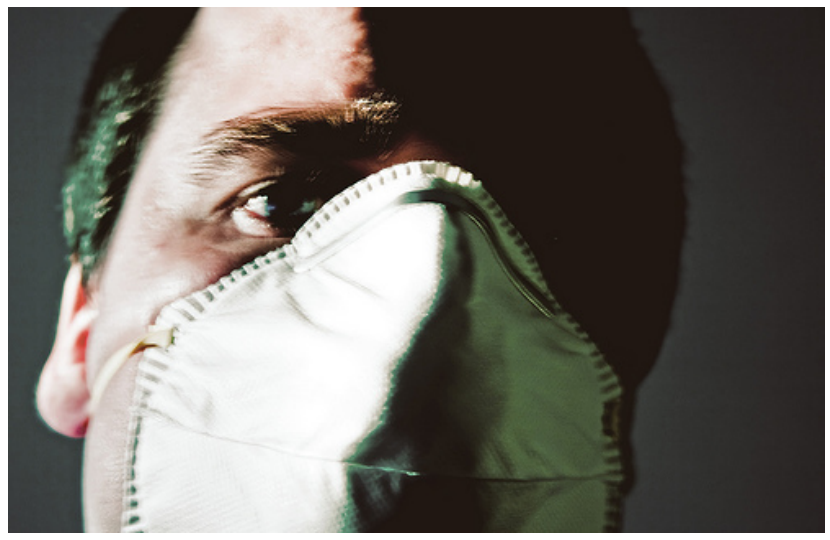

Contemporary populations have also associated H1N1 flu susceptibility with levels of sexual activity. ${ }^{2}$

The archetypal phenomenon of "symbolic" disease protection could explain why governments were caught off guard by the public's apparent indifference to the availability of a vaccine in the fall and winter following the H1N1 outbreak, despite the earlier panic. ${ }^{7,9}$ A majority of individuals assessed the level of risk posed by H1N1 through its presence in individual communities, ${ }^{9}$ or through the opinions of peer groups, which could either heighten ${ }^{2}$ or lessen risk.

Implicit in the development of public health messages during the H1N1 pandemic was the attempt to anticipate the motivations behind human behavior: what messages would create adherence to advised public health measures? A framework tying the application of epidemic response archetypes to human motivation is suggested by Kenneth Burke, whose book A Grammar of Motives rests on the central question, "What is involved, when we say what people are doing and why they are doing it?"10

Because of his interest in issues of "universal" significance, ${ }^{11}$ Burke's theories have impacted numerous disciplines, including medicine. ${ }^{12,13}$ Burke argues that aspects of situations can be categorized via the terms "Act, Scene, Agent, 
Agency, [and] Purpose," which together form the "dramatist pentad." to reveal human motivation. ${ }^{10}$ By identifying these key elements in a situation or projected scenario, an observer can determine which element exerts the most influence, and proceed toward possible consequences. As part of a scenario development process in pandemic planning, the pentad could improve the authenticity of a given scenario ${ }^{14}$ and take regional influences on populations into account, such as epidemic threats from additional sources of infection (e.g., avian influenza). ${ }^{2}$

Burke recognized that in catastrophic situations, a "scene-act" ratio would prevail. The scene would govern which acts took place: one could look to the behavior of the participants for expression of "the motivating influence of the crisis." 15 When the primary motivating influence becomes something other than the crisis itself, audiences of public health messages may act in unexpected ways. During the H1N1 outbreak, a contagion of indifference to $\mathrm{H} 1 \mathrm{~N} 1$, or ambivalence toward the $\mathrm{H} 1 \mathrm{~N} 1$ vaccine, ${ }^{7,9}$ overshadowed literal contagion in public health significance. The pentad could highlight what epidemic response archetypes may play a role in a given situation-such as the H1N1 pandemic "scene" involving a concurrent decline in mortalities and increase in vaccine availability. In short, Burke's pentad enables investigation of a number of perspectives based on examination of the five elements of a situation, ${ }^{10}$ while epidemic response archetypes provide variables for consideration in those perspectives.

Epidemic response archetypes are available in the historical record and thus represent tools in pandemic planning. It has been said that "H1N1dsight is a wonderful thing." be a glimpse of the future.

\section{Acknowledgements}

I would like to thank John Moffatt for his critical review of the manuscript and the anonymous reviewers from Health Science Inquiry for their constructive insights. I gratefully acknowledge the support of the Ron \& Jane Graham Graduate Scholarship.

\section{References}

1 Bilson G. The first epidemic of Asiatic Cholera in Lower Canada, 1832. Med Hist [Internet]. 1977 [cited 2010 Mar 21]; 21(4):411-433. Available from:

http://www.ncbi.nlm.nih.gov/pmc/articles/PMC1082085/
2 Goodwin R, Haque S, Neto F, Myers L. Initial psychological responses to Influenza A, H1N1 ("Swine flu"). BMC Infectious Diseases [Internet]. 2009 Oct [cited 2010 Apr 17]; 9:166-171. Available from: http://www.biomedcentral.com/1471-2334/9/166

3 Rosenberg CE. Explaining epidemics and other studies in the history of medicine. Cambridge: Cambridge University Press; 1992.

4 Eichelberger L. SARS and New York's Chinatown: The politics of risk and blame during an epidemic of fear. Social Science \& Medicine 2007; 65:1284-1295.

5 Branswell H. Mystery illness found in tourists to Mexico: Health officials told to check returning Canadians. The Edmonton Sun. Friday April 24 2009:p.54.

6 Alphonso C. Travel Health Advisory: Back from Mexico? Watch for flu-like illness. Travellers urged to be aware as mysterious respiratory infections cause Mexican authorities to ask Canada for investigative help. Globe and Mail. Friday April 24 2009:p.A3.

7 Ofri D. The emotional epidemiology of H1N1 influenza vaccination. N Engl J Med [Internet]. 2009 Dec [cited 2010 Mar 21]; 361:2594-2595. Available from: http://content.nejm.org/cgi/content/full/NEJMp0911047

8 H1N1dsight is a wonderful thing. Nat Biotechnol 2010; 28(3): 182.

9 SteelFisher GK, Blendon RJ, Bekheit MM, Lubell, K. The public's response to the $2009 \mathrm{H} 1 \mathrm{~N} 1$ influenza pandemic. N Engl J Med [Internet]. 2010 May 19 [cited 2010 May 21]. Available from: http://content.nejm.org/cgi/content/full/NEJMp1005102

10 Burke K. A grammar of motives. Berkeley: University of California Press; 1969.

11 Brummett B, Young AM. Some uses of Burke in Communication Studies. K.B. Journal [Internet]. 2006 Spring [cited 2010 Mar 21]; 2(2). Available from: http://kbjournal.org/node/115/86

12 Jodlowski D, Sharf BF, Nguyen LC, Haidet P, Woodard LD. 'Screwed for life': examining identification and division in addiction narratives. Commun Med 2007; 4(1):15-26.

13 Whyte S, Cartmill C, Gardezi F, Reznick R, Orser BA, Doran D, Lingard L. Uptake of a team briefing in the operating theatre: A Burkean dramatistic analysis. Soc Sci Med 2009; 69(12):1757-1766.

14 Shearer AW. Applying Burke's Dramatic Pentad to scenarios. Futures 2004; 36:823-835.

15 Burke K. Questions and answers about the pentad. College Composition and Communication 1978; 29(4):330-335.

\section{Author Profile}

Tess Laidlaw is currently pursuing a $\mathrm{PhD}$ degree in Rhetoric \& Popular Culture at the Graham Centre for the Study of Communication (University of Saskatchewan). She had previously completed a MA degree in journalism at the University of Western Ontario, and is mainly interested in studying the rhetoric of disease and medicine, and the role that science plays in society. 